\section{SAT0203 SINGLE LAC POSITIVITY VERSUS DOUBLE AND TRIPLE POSITIVITY FOR THROMBOSIS IN SLE}

S. Demir ${ }^{1}, 2$, J. Li ${ }^{1}$, L. Magder ${ }^{3}$, M. A. Petri ${ }^{1}{ }^{1}$ Johns Hopkins University, Department of Rheumatology, Baltimore, United States of America; ${ }^{2}$ Hacettepe University Faculty of Medicine, Department of Pediatric Rheumatology, Ankara, Turkey; ${ }^{3}$ University of Maryland School of Medicine, Department of Epidemiology and Public Health, Baltimore, United States of America

Background: The antiphospholipid syndrome (APS) is defined by the development of venous and/or arterial thromboses, and pregnancy morbidity, in the presence of antiphospholipid antibodies (aPL); lupus anticoagulant, moderate-to-high titer anticardiolipin $(\mathrm{aCL})$ and anti- $\beta 2$-glycoprotein $(\mathrm{aB} 2 \mathrm{GPI})$. It has been suggested that the incidence of thromboembolic events were significantly higher in the triple positive subjects, and the rate of pregnancy loss was also significantly much higher in double positive subjects (1). On the other hand several studies showed that LAC is more highly associated with thrombosis risk (2).

Objectives: We aimed to investigate the risk of thrombosis in Systemic Lupus Erythematosus (SLE) patients with single LAC positivity versus double and triple positivity in Hopkins Lupus Cohort.

Methods: The Hopkins Lupus Cohort is a prospective longitudinal cohort of SLE patients ongoing since 1987. This analysis was based on cohort experience from 2003 through October 2019. Anticardiolipin and anti-Beta2 glycoprotein were defined as positive when the antibody titer exceeded 20 units. The lupus anticoagulant was determined by dilute Russell's viper venom time (dRVVT) and confirmatory mixing studies, if prolonged. It is defined as positive if a patient had a dRVVT of 45 or more second and a positive confirm ratio of more than 1.4. For each aPL, we defined the patient as positive at a given month of follow up if they ever had a positivity in previous measures. The relationships between thrombosis and $\mathrm{aPL}$ were adjusted for number of prior $\mathrm{PPL}$ assessment.

Results: There were 805 patients with a complete profile of 7 antiphospholipid antibodies, with a total of 73417 person months (6118 person years) of follow up. For any thrombosis when compared to patients with LAC positivity only, double positivity with any isotypes $[1.15(0.50,2.66) p=0.7484]$ and triple positivity with any isotypes $[1.68(0.74,3.80), p=0.2145]$ showed a higher point estimates but statistically not significant (Table 1).

Table 1. Single, double and triple positive patterns and the risk of any thrombosis.

\begin{tabular}{lccccc}
\hline Pattern & $\begin{array}{c}\text { Number of } \\
\text { events }\end{array}$ & $\begin{array}{c}\text { Person- } \\
\text { years }\end{array}$ & $\begin{array}{c}\text { Rate per } 1000 \\
\text { person-years }\end{array}$ & $\begin{array}{c}\text { adjusted RR } \\
(95 \% \mathrm{Cl})\end{array}$ & p-value \\
\hline LAC positivity only & 10 & 633 & 15.8 & $1.00(\mathrm{Ref})$ & \\
Never any aPL & 33 & 2581 & 12,8 & $0.73(0.36,1.47)$ & 0.3819 \\
any aCL positivity only & 6 & 793 & 7,6 & $0.43(0.16,1.18)$ & 0.1028 \\
any aB2GPI positivity only & 7 & 517 & 13,5 & $0.78(0.30,2.05)$ & 0.6195 \\
any aCL and aB2GPI posi- & 5 & 404 & 12,4 & $0.71(0.24,2.04)$ & 0.5211 \\
$\quad$ tivity only & 7 & 406 & 17,3 & $1.15(0.50,2.66)$ & 0.7484 \\
LAC and ACL positivity & 12 & 490 & 24,5 & & \\
LAC and aB2GPI positivity & 0 & 147 & 0,0 & $1.68(0.74,3.80)$ & 0.2145 \\
Triple positivity & & & & & \\
\hline
\end{tabular}

Conclusion: We found that triple or double positive aPL profiles are not superior to single LAC positivity in their association with any thrombosis in SLE patients. References:

[1] Pengo V, Ruffatti A, Del Ross T, Tonello M, Cuffaro S, Hoxha A, Banzato A,Bison E, Denas G, Bracco A, Padayattil Jose S. Confirmation of initial antiphospholipid antibody positivity depends on the antiphospholipid antibody profile. J Thromb Haemost. 2013 Aug;11(8):1527-31.

[2] Galli M, Luciani D, Bertolini G, Barbui T. Lupus anticoagulants are stronger risk factors for thrombosis than anticardiolipin antibodies in the antiphospholipid syndrome: a systematic review of the literature. Blood. 2003; 101(5):1827-32.

Disclosure of Interests: Selcan Demir: None declared, Jessica Li: None declared, Laurence Magder: None declared, Michelle A Petri Grant/research support from: GSK, Eli Lilly and Company, Consultant of: Eli Lilly and Company DOI: 10.1136/annrheumdis-2020-eular.2762

\section{SAT0204 COMPARING OCCURRENCE AND CLINICAL SIGNIFICANCE OF ANTI-PHOSPHOLIPID AUTOANTIBODIES AMONG SUDANESE AND SWEDISH SLE PATIENTS USING CONVENTIONAL AND NATION- BASED CUTOFFS}

S. Elbagir ${ }^{1}$, A. Elshafie ${ }^{1}$, E. M. Elagib ${ }^{2}$, N. A. Mohammed ${ }^{3}$, V. A. Manivel ${ }^{1}$, E. Pertsinidou' ${ }^{1}$, M. A. M. Nur ${ }^{4}$, I. Gunnarsson ${ }^{5}$, E. Svenungsson ${ }^{5}$, J. Rönnelid ${ }^{1}$ ${ }^{1}$ Uppsala University, Immunology, Genetics and Pathology, Uppsala, Sweden; ${ }^{2}$ Military Hospital, Rheumatology Únit, Omdurman, Sudan; ${ }^{3}$ Al Neelain University, Khartoum, Sudan; ${ }^{4}$ Alribat University Hospital, Rheumatology Unit, Khartoum,
Sudan; ${ }^{5}$ Karolinska University Hospital, Division of Rheumatology, Department of Medicine Solna, Stockholm, Sweden

Table 1.

\begin{tabular}{|c|c|c|c|c|c|c|}
\hline & $\begin{array}{l}\text { FEIA } \\
\text { Sudan } \\
n=92\end{array}$ & $\begin{array}{c}\text { FEIA } \\
\text { Sweden } \\
n=291\end{array}$ & $P$ & $\begin{array}{c}\mathrm{PMAT} / \mathrm{CIA} \\
\text { Sudan } \\
\mathrm{n}=93\end{array}$ & $\begin{array}{c}\mathrm{PMAT} / \mathrm{ClA} \\
\text { Sweden } \mathrm{n}=333\end{array}$ & $P$ \\
\hline $\begin{array}{l}\text { IgA CL median/ } \\
\text { IQR }\end{array}$ & $6.5 / 5.2$ & $4.0 / 4.1$ & $<0.0001$ & $194 / 185$ & $148 / 112$ & $<0.0001$ \\
\hline $\operatorname{lgG}$ CL & $4.1 / 5.1$ & $3.0 / 4.5$ & 0.0002 & 205/137 & $190 / 215.1$ & 0.09 \\
\hline $\operatorname{lgM} C L$ & $2.7 / 6.8$ & $3.7 / 5.4$ & 0.02 & $214 / 251.5$ & $193 / 3502$ & 0.2 \\
\hline IgA $\beta 2 G P I$ & $6.3 / 14.2$ & $2.7 / 3.8$ & $<0.0001$ & $212 / 347$ & $118 / 152$ & $<0.0001$ \\
\hline IgG $\beta 2 \mathrm{GPI}$ & $4.2 / 2.9$ & $1.8 / 2.3$ & $<0.0001$ & $158 / 110.7$ & $145.2 / 147.5$ & 0.04 \\
\hline IgM $\beta 2 G P I$ & $2.0 / 3.0$ & $1.4 / 2.2$ & 0.006 & $146.2 / 189.7$ & $132.5 / 235.4$ & 0.09 \\
\hline IgA B2GP1 D1 & & & & $1542 / 1253.5$ & $1683 / 1518.1$ & 0.045 \\
\hline $\begin{array}{l}\text { IgA CL common } \\
\text { cutoff } n(\%)\end{array}$ & $9(9.8)$ & $17(5.8)$ & 0.2 & 32(35.2) & 75(22.7) & 0.02 \\
\hline $\operatorname{lgG} C L$ & $4(4.3)$ & $21(6.7)$ & 0.4 & $14(15)$ & $72(22.1)$ & 0.1 \\
\hline IgM CL & $3(3.2)$ & $14(4.5)$ & 0.6 & 10(11.4) & $43(13.1)$ & 0.6 \\
\hline IgA $\beta 2 G P I$ & $32(34.8)$ & $43(14.9)$ & $<0.0001$ & $38(41.8)$ & $76(23)$ & 0.0004 \\
\hline IgG $\beta 2 G P I$ & $10(10.9)$ & $44(14.1)$ & 0.4 & $5(5.4)$ & $50(15.3)$ & 0.01 \\
\hline IgM $\beta 2 G P I$ & $10(10.9)$ & $27(8.7)$ & 0.5 & $12(13.6)$ & $42(12.9)$ & 0.8 \\
\hline IgA B2GP1 D1 & & & & $6(6.4)$ & $38(11.4)$ & 0.2 \\
\hline $\begin{array}{l}\text { IgA CL } 95^{\text {th }} \text { cutoff } \\
\mathrm{n}(\%)\end{array}$ & $9(9.8)$ & $54(18.6)$ & 0.047 & $36(39.6)$ & $121(26.6)$ & 0.6 \\
\hline $\operatorname{lgG} \mathrm{CL}$ & $8(8.7)$ & $42(13.5)$ & 0.2 & $24(25.8)$ & $103(31.6)$ & 0.3 \\
\hline $\lg M C^{2}$ & $8(8.7)$ & $39(12.5)$ & 0.3 & $16(18.2)$ & $47(14.4)$ & 0.4 \\
\hline IgA $\beta 2 G P I$ & $18(19.6)$ & $100(34.7)$ & 0.006 & $20(22)$ & $125(37.8)$ & 0.005 \\
\hline IgG $\beta 2$ GPI & $2(2.1)$ & $67(21.5)$ & $<0.0001$ & $19(20.4)$ & $83(25.5)$ & 0.3 \\
\hline IgM $\beta 2 G P I$ & 14(15.22) & $57(18.3)$ & 0.5 & $20(22.7)$ & $57(17.5)$ & 0.3 \\
\hline IgA B2GP1 D1 & & & & $25(26.9)$ & $69(20.7)$ & 0.2 \\
\hline
\end{tabular}
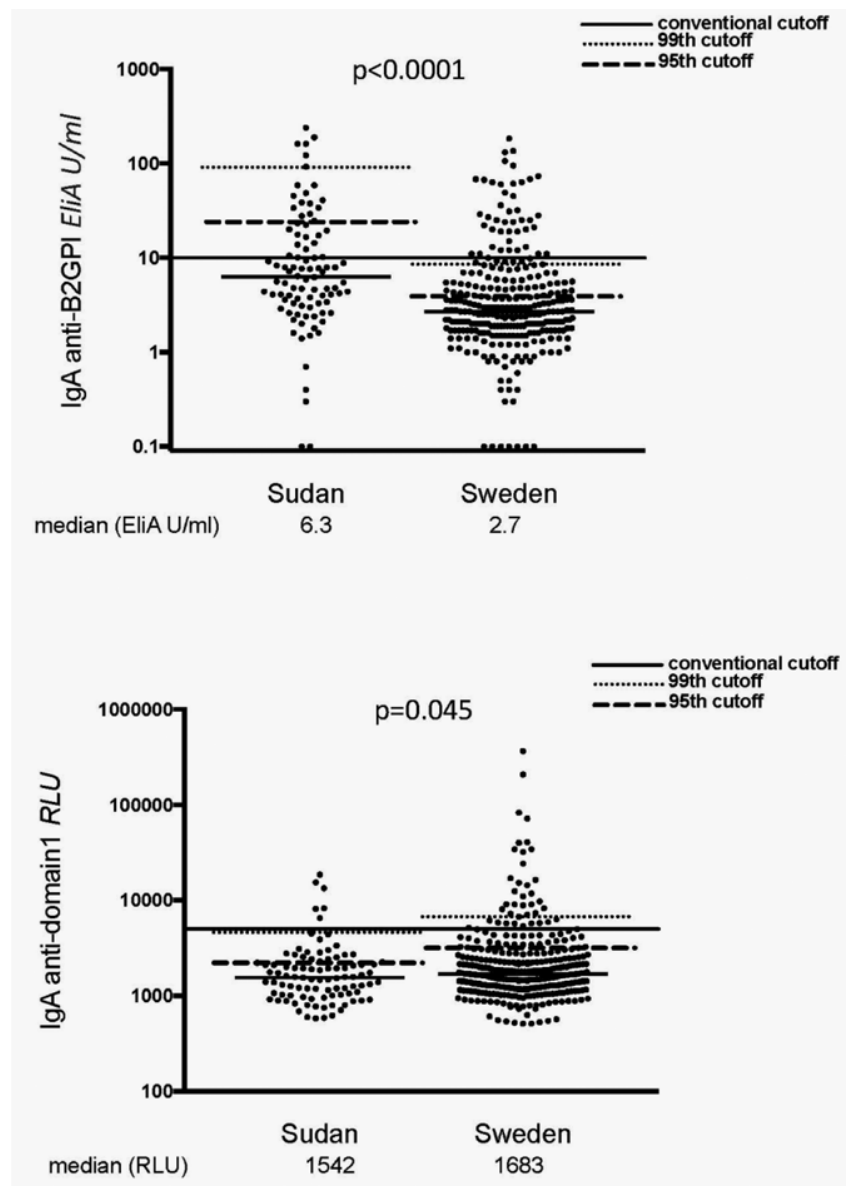

Figure 1.

Background: Antiphospholipid antibodies (aPL) of IgA isotype are prevalent in SLE patients of African-American, Afro-Caribbean and South-African origin, but data from North Africa are lacking

Objectives: To compare and determine clinical significance of aPL isotypes in Sudanese and Swedish SLE patients using nation-based cutoffs 
Methods: Consecutive Sudanese $(n=115)$ and Swedish $(n=340)$ SLE patients and 106 and 318 age- and sex-matched national controls were included. All patients fulfilled the 1982 ACR SLE classification criteria. IgA/G/M anti-cardiolipin and anti- $\beta_{2}$ GPI were analyzed with two independent assays (Fluorescence Enzyme Immuno Assay (FEIA) from Thermo Fisher Scientific and Particle-based Multi-Analyte Technology (PMAT) from Inova Diagnostics). IgA anti- $\beta$ GPI domain1 (D1) was investigated with chemiluminescence (CIA), Inova Diagnostics. APS-related events were obtained from patients' records. Manufacturers', $95^{\text {th }}$ and $99^{\text {th }}$ percentile cutoffs, based on national controls calculated by non-parametric methods, were used

Results: Sudanese patients had higher levels and prevalence of $\lg \mathrm{A}$ aPL using manufacturers' cutoffs (Table 1 and Figure 1). IgA/lgG aPL were also higher among Sudanese controls, But, Swedish patients were more often positive for IgA anti- $\beta_{2}$ GPI with both assays when national cutoffs were applied (Table 1). Occurrence of IgA anti-D1 did not differ between the countries. Venous thromboses were less common among Sudanese patients and no aPL, including IgA anti- $\beta_{2}$ GPI associated with thrombosis in Sudanese patients. Thrombosis in Swedes associated with $\mathrm{lgG} / \mathrm{lgM}$ aPL. Fetal loss associated with $\mathrm{aPL}$ in both cohorts most evident after national adjustments

Conclusion: IgA anti- $\beta_{2}$ GPI levels were generally higher among Sudanese compared to Swedish SLE patients and controls, but after national adjustments more Swedish than Sudanese patients were positive. IgA anti-D1 was not increased in Sudanese patients. Previous studies on populations of African-origin, which demonstrate high prevalence of IgA aPL positivity, should be re-evaluated using similar cutoff approach Acknowledgments: : We thank Maryam Poorafshar at Thermo Fischer Scientific and Silvia Casas and Michael Mahler at Inova Diagnostics for help with analyses Disclosure of Interests: None declared

DOI: 10.1136/annrheumdis-2020-eular.2812

\section{SAT0205 A MORE SPECIFIC INTEGRATED MODEL FOR IDENTIFYING BACTERIAL INFECTION IN SYSTEMIC LUPUS ERYTHEMATOSUS}

M. Feng ${ }^{1}$, X. C. Zhao ${ }^{1}$, J. Luo ${ }^{1} .{ }^{1}$ The Second Hospital of Shanxi Medical University, Taiyuan, China

Background: Systemic lupus erythematosus (SLE) is a multisystemic inflammatory disorder [1]. Given that immunosuppressive therapy is adopted as the predominant treatment option for SLE, up to half of SLE patients develop infections during their disease progress, and bacterial infection serves as the leading cause of morbidity and mortality in SLE patients [2]. Owing to the therapeutic regimen to bacterial infection and SLE flare are absolutely opposite, timely diagnosis and correct treatment are of vital importance, and improper treatment strategy may be fatal. No single biomarker, however, has exhibited sufficient sensitivity and specificity to serve as a standard tool for distinguishing bacterial infection from SLE flare. Objectives: To find a method by integrating cytokines, lymphocyte cells and routine examination biomarkers to observe its capacity for identifying bacterially infected SLE patients.

Methods: Total 175 SLE patients (65 infected and 110 flare) were recruited into our study. The criteria of bacterial infection was positive isolation of bacteria, typical clinical symptoms and signs, imaging positive results and positive feedback on antibacterial treatment and lupus flare was regarded as three points higher than their previous SLEDAI. The disease activity of SLE patients was evaluated based on Systemic Lupus Erythematosus Disease Activity Index (SLEDAI). Lymphocyte cells $\left(\mathrm{CD}^{+} \mathrm{T}, \mathrm{CD}^{+} \mathrm{T}, \mathrm{CD}^{+} \mathrm{T}, \mathrm{B}, \mathrm{NK}, \mathrm{Th} 1, \mathrm{Th} 2, \mathrm{Th} 17\right.$ and Treg) and cytokines [interleukin-2 (IL-2), IL-4, IL-6, IL-10, tumor necrosis factor-a (TNF-a), interferon- $\gamma$ (IFN- $\gamma)$ and IL-17] were measured by flow cytometry. Blood routine examination, erythrocyte sedimentation rate (ESR), C-Reactive Protein (CRP) Complement 3 (C3), C4, procalcitonin (PCT), immunoglobulin M (IgM), IgA and IgG were also evaluated. Partial least square discriminant analysis (PLS-DA) and supervised orthogonal PLS-DA (OPLS-DA) were applied to perform multivariate analysis of the data and further group the patients with bacterial infection. Receiver operating characteristic $(\mathrm{ROC})$ curves were also plotted to investigate the ability of individual indicator and the combination of multiple indicators to identify bacterial infection. Results: The PLS-DA model showed a clear identification effect by the performance of $R 2 Y=0.991$ and $Q 2=0.970$. The OPLS-DA model $(R 2 Y=0.996$ and $\mathrm{Q} 2=0.991$ ) exhibited a better separation of patients with bacterial infection. And the Observed vs. predicted plot of the OPLS-DA model demonstrated that all SLE patients were correctly separated into infected or flare groups, indicating that the model had a strong predictive ability for bacterial infection. For single indicator, infected patients had higher WBC, neutrophil (NEUT), ESR, CRP and PCT $(P=0.002,0.019,0.002,<0.001,<0.001$, respectively), and lower Treg cells $(P=0.012)$. The levels of serum IL-6, IL-10, IFN- $\gamma$ and TNF-a $(P<0.001,=0.022$, $0.014,0.011$, respectively) were significantly increased in infected group. ROC curves showed that the combination of the ten indicators showed the largest AUC and the highest accuracy, as well as balanced and relatively high sensitivity and specificity. Furthermore, the AUC of the combination was greatly higher than that of WBC, NEUT, ESR, CRP, PCT, Treg, IL-6, IL-10, IFN- $\gamma$ and TNF- $a(P<0.001)$. Conclusion: PLS-DA, OPLS-DA models including cytokines, lymphocyte cells and routine biomarkers and combination of WBC, NEUT, ESR, CRP, PCT, Treg,

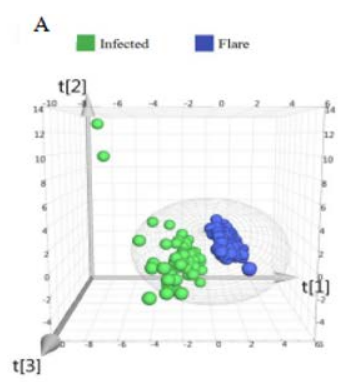

B

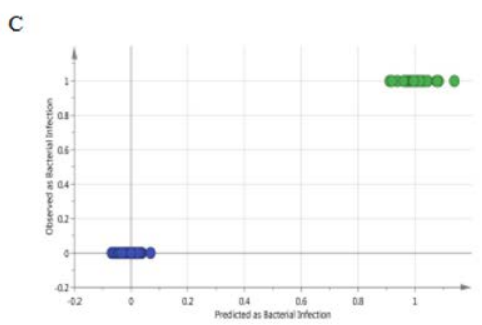

Figure 1. Identification of systemic lupus erythematosus (SLE) patients with bacterial Figure 1. Identification of systemic lupus erythematosus (SLE) patients with bactenal
infection and Flare by using partial least square discriminant analysis (PLS-DA) and infection and Flare by using partial least square discriminant analysis (PLS-DA) and
orthogonal PLS-DA (OPLS-DA) methods. (A) Three-dimensional PLS-DA score scatter plot, (B) the OPL S-DA score scatter plot and (C) the 'Predicted vs. Observed' plot for distinguishing bacterially infected SLE patients (green dots) from non-bacterially infected SLE patients (blue dots) based on 50 indicators. Both groups were greatly separated in the PLS-DA and OPLS-DA models. None of the non-infected SLE patients were predicted as a lupus flare

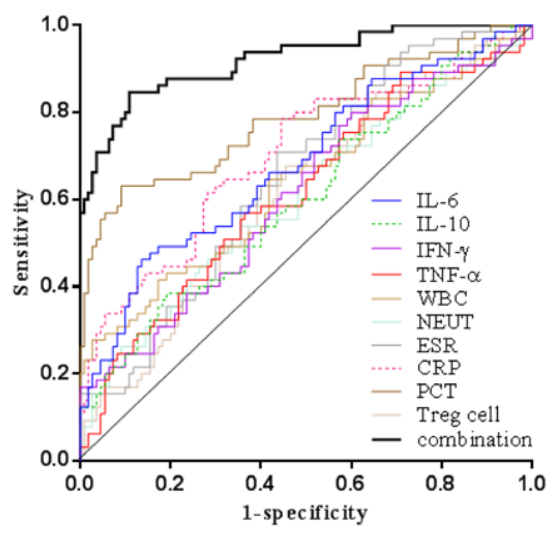

Figure 2. Receiver operating characteristic (ROC) curves of WBC, NEUT, ESR, CRP, PCT, Treg cells, $\mathbb{L}-6, \mathbb{L}-10, \mathbb{F} N-\gamma$, TNF- $\alpha$ and their combination were drawn to identify systemic lupus erythematosus (SLE) patiens with or without bacterial infection.

\begin{tabular}{|c|c|c|c|c|c|c|}
\hline biomarker & $\begin{array}{c}\text { AUC (\%) } \\
95 \% \mathrm{CI}\end{array}$ & $\begin{array}{c}\text { Accuracy } \\
(\%)\end{array}$ & $\begin{array}{c}\text { Sensitivity(\%) } \\
95 \% \mathrm{CI}\end{array}$ & $\begin{array}{c}\text { Specificity(\%) } \\
95 \% \text { CI }\end{array}$ & $\begin{array}{c}\text { PLR/NLR } \\
(\%)\end{array}$ & $\begin{array}{c}\text { PPV/NPV } \\
(\%)\end{array}$ \\
\hline WBC & $\begin{array}{c}0.641 \\
(0.565-0.712)\end{array}$ & 71.43 & $\begin{array}{c}27.69 \\
(17.31-40.19)\end{array}$ & $\begin{array}{c}97.27 \\
(92.24-99.43)\end{array}$ & $10.15 / 0.74$ & $85.71 / 69.48$ \\
\hline NEUT & $\begin{array}{c}0.606 \\
(0.529-0.679)\end{array}$ & 60.57 & $\begin{array}{c}53.85 \\
(41.03-66.30)\end{array}$ & $\begin{array}{c}64.55 \\
(54.85-73.43)\end{array}$ & $1.52 / 0.72$ & $47.29 / 70.30$ \\
\hline ESR & $\begin{array}{c}0.637 \\
(0.561-0.708)\end{array}$ & 61.14 & $\begin{array}{c}63.08 \\
(50.20-74.72)\end{array}$ & $\begin{array}{c}60.00 \\
(50.22-69.22)\end{array}$ & $1.58 / 0.62$ & $48.23 / 73.34$ \\
\hline CRP & $\begin{array}{c}0.702 \\
(0.628-0.768)\end{array}$ & 64.00 & $\begin{array}{c}78.46 \\
(66.51-87.69)\end{array}$ & $\begin{array}{c}55.45 \\
(45.67-64.93)\end{array}$ & $1.76 / 0.39$ & $51.00 / 81.34$ \\
\hline PCT & $\begin{array}{c}0.785 \\
(0.717-0.843)\end{array}$ & 80.57 & $\begin{array}{c}56.92 \\
(44.04-69.15)\end{array}$ & $\begin{array}{c}94.55 \\
(88.51-97.97)\end{array}$ & $10.44 / 0.46$ & $86.05 / 78.79$ \\
\hline Treg & $\begin{array}{c}0.614 \\
(0.538-0.687)\end{array}$ & 59.43 & $\begin{array}{c}67.69 \\
(54.95-78.77)\end{array}$ & $\begin{array}{c}54.55 \\
(44.77-64.07)\end{array}$ & $1.49 / 0.59$ & $46.81 / 74.08$ \\
\hline IL -6 & $\begin{array}{c}0.682 \\
(0.607-0.750)\end{array}$ & 70.29 & $\begin{array}{c}49.23 \\
(36.60-61.93)\end{array}$ & $\begin{array}{c}82.73 \\
(74.35-89.27)\end{array}$ & $2.85 / 0.61$ & $62.74 / 73.39$ \\
\hline IL-10 & $\begin{array}{c}0.603 \\
(0.527-0.676)\end{array}$ & 65.14 & $\begin{array}{c}38.46 \\
(26.65-51.36)\end{array}$ & $\begin{array}{c}80.91 \\
(72.31-87.78)\end{array}$ & $2.01 / 0.76$ & $54.34 / 68.99$ \\
\hline IFN $-\gamma$ & $\begin{array}{c}0.611 \\
(0.535-0.684)\end{array}$ & 54.86 & $\begin{array}{c}80.00 \\
(68.23-88.90)\end{array}$ & $\begin{array}{c}40.00 \\
(30.78-49.78)\end{array}$ & $1.33 / 0.50$ & $44.06 / 77.20$ \\
\hline TFN- $\alpha$ & $\begin{array}{c}0.616 \\
(0.539-0.688)\end{array}$ & 68.15 & $\begin{array}{c}56.92 \\
(44.04-69.15)\end{array}$ & $\begin{array}{c}63.64 \\
(53.92-72.60)\end{array}$ & $1.57 / 0.68$ & $48.05 / 71.43$ \\
\hline Combined & $\begin{array}{c}0.921 \\
(0.870-0.956)\end{array}$ & 87.43 & $\begin{array}{c}84.62 \\
(73.52-92.37)\end{array}$ & $\begin{array}{c}89.09 \\
(81.72-94.23)\end{array}$ & $7.76 / 0.17$ & $82.09 / 90.74$ \\
\hline
\end{tabular}

AUC: area under the ROC curve; CI, confidence interval; PLR, positive likely ratio; NLR, negative likely ratio; PPV, positive predictive value; NPV, negative predictive value, WBC, white blood cell; NEUT, neutrophile granulocyte; ESR, erythrocyte sedimentation rate; CRP: C-reactive protein; PCT: procalcitonin; IL-6, interleukin-6; IL-10, interleukin-10; IFN- $\gamma$, interferon- $x$, TNF- $\alpha$, tumor necrosis factor- $\alpha$. 